Letters to the Editor

\title{
Determination of Trace Elements in Minute Masses of Fresh Sample by "One-Drop" Inductively Coupled Plasma Atomic Emission Spectrometry
}

\author{
Isao KoJIMA*, Tetsuo UchidA*, Chuzo IIDA*, Kouichi IEdA** and Takeo MukaI** \\ *Laboratory of Analytical Chemistry, Department of Applied Chemistry, Nagoya Institute of \\ Technology, Gokiso, Showa, Nagoya 466 \\ **Central Hospital, 5-11, Sakae, Naka, Nagoya 460
} Keywords Fresh liver, one-drop method, Teflon bomb, trace metals, inductively coupled plasma atomic emission
spectrometry

The "one-drop" method in atomic spectrometry 1 "- is the most favorable one for the determination of elements in very minute and limited volumes of sample solutions, after proper chemical pretreatments of solid samples. This method has been successfully applied to the determination of rather high concentration of elements in some standard materials less than $10 \mathrm{mg}$, after the sample decomposition with an acid mixture in a sealed Teflon bomb at elevated temperature. ${ }^{5}$ With special reference to the precise determination of trace elements in a very minute and limited sample mass, the following conditions are required: 1) Final sample solution obtained from such sample size after proper chemical treatment must be a small volume to keep metal concentrations higher. 2) A small volume of sample solution for each determination should be used. 3) Repeated measurements for a metal should be avoided, owing to the small final sample volume. 4) A method with a wide and effective dynamic range and less interference from coexisting elements should be used for determination. When we take these requirements into consideration, we can see how very important it is that a method be developed for the reliable determination of trace elements in a very minute and limited sample mass by only one measurement per element. For this purpose, one-drop inductively coupled plasma atomic emission spectrometry (ICPAES) with a wide and effective dynamic range seems to be reasonable.

The present paper describes the precise determination of ppm levels of copper, lead, manganese and cadmium in very minute and limited masses of fresh liver by one-drop ICP-AES with an injection volume of $100 \mu \mathrm{l}$ per each metal, without high dilution of the sample in preparing sample solutions.

\section{Experimental}

\section{Apparatus}

ICP-AES measurements were carried out under the optimum operating conditions determined in our laboratory (See Table 1) by a Nippon Jarrell-Ash Model ICAP-575 with a specially designed small Teflon cup for sample injection ${ }^{4}$ and an automatic trigger of photocoupler type. ${ }^{6}$ The dilution of sample and standard solutions and injection of $100 \mu \mathrm{l}$ of these solutions were done with micropipettes from Gilson.

\section{Reagents}

Metal stock solutions $\left(2 \mathrm{mg} / \mathrm{g}\right.$ in $0.5 \mathrm{~mol} \mathrm{dm}^{-3} \mathrm{HNO}_{3}$ or $\mathrm{HCl})$ were prepared by dissolving metals $(\mathrm{Cu}, \mathrm{Pb}$ and $\mathrm{Cd}$ of $99.999 \%$, Mitsuwa Chemicals) and man-

Table 1 Operating conditions for ICP-AES

\begin{tabular}{|c|c|c|c|}
\hline \multicolumn{2}{|c|}{ Grating } & \multicolumn{2}{|c|}{1800 grooves $/ \mathrm{mm}$} \\
\hline \multicolumn{2}{|c|}{ Spectrometer } & \multicolumn{2}{|c|}{ Czerny-Turner Mount $(0.75 \mathrm{~m})$} \\
\hline & \multicolumn{2}{|c|}{$1.2 \mathrm{~kW}$} \\
\hline \multicolumn{2}{|c|}{ Photomultiplier } & \multicolumn{2}{|c|}{ Hamamatsu R-427 (Solar blind) } \\
\hline \multicolumn{2}{|c|}{ Argon gas } & \multicolumn{2}{|c|}{$16-0.5-0.431 / \mathrm{min}$} \\
\hline \multicolumn{2}{|c|}{ Slit } & \multicolumn{2}{|c|}{$25 \mu \mathrm{m}$} \\
\hline \multicolumn{2}{|c|}{ Observation height } & \multicolumn{2}{|c|}{$12.5 \mathrm{~mm}$ above coil } \\
\hline \multicolumn{2}{|c|}{ Integration time } & \multicolumn{2}{|c|}{$9 \mathrm{~s}$} \\
\hline \multicolumn{2}{|c|}{ Sample flow rate } & \multicolumn{2}{|l|}{$1.9 \mathrm{ml} / \mathrm{min}$} \\
\hline \multicolumn{4}{|c|}{ High salt concentration torch with cross flow nebulizer } \\
\hline Element & Wavelength & High voltage & $\begin{array}{l}\text { Concentration for } \\
\text { calibration }\end{array}$ \\
\hline $\mathbf{P b}$ & $220.353 \mathrm{~nm} \times 2$ & $900 \mathrm{~V}$ & $0-1.0 \mu \mathrm{g} / \mathrm{g}$ \\
\hline $\mathrm{Cu}$ & $224.700 \mathrm{~nm} \times 3$ & $900 \mathrm{~V}$ & $0-1.0 \mu \mathrm{g} / \mathrm{g}$ \\
\hline Mn & $257.619 \mathrm{~nm} \times 2$ & $600 \mathrm{~V}$ & $0-1.0 \mu \mathrm{g} / \mathrm{g}$ \\
\hline $\mathrm{Cd}$ & $214.438 \mathrm{~nm} \times 3$ & $900 \mathrm{~V}$ & $0-1.0 \mu \mathrm{g} / \mathrm{g}$ \\
\hline
\end{tabular}

Nippon Jarrell-Ash, Model ICAP-575. 
ganese dioxide ("Specpure", Johnson Matthey) in nitric or hydrochloric acid and diluting with water by mass. Working mixed standard solutions were prepared by diluting the stock solutions with water and perchloric acid by mass to the appropriate concentrations. These solutions contain the same concentration of perchloric acid as in the sample solution. The acids used were of super special grade quality from Wako Pure Chemicals. Doubly distilled water from an allglass still was used throughout.

\section{Decomposition of fresh sample}

A fresh liver sample $(39.9 \mathrm{mg}$ ) biopsied from a male patient suspected of having lead poisoning, judging from his past occupational record, i.e., glazer, was taken directly into a PFA Tuf-Tainer vial (perfluoroalkoxyethylene, $7.0 \mathrm{ml}$ capacity, TV-7, Pierce Chemical) previously weighed. Three hundred microliters of nitric acid, $20 \mu \mathrm{l}$ each of hydrochloric and perchloric acids were added in the vial. This vial was placed in a Teflon vessel of $23 \mathrm{ml}$ capacity with a stainless steel jacket. After fastening the stainless steel cap tightly with a wrench, decomposition was carried out by consecutive heating of the bomb at $90^{\circ} \mathrm{C}$ for $2 \mathrm{~h}$ and then $140^{\circ} \mathrm{C}$ for $2 \mathrm{~h}$ in an air oven. ${ }^{5}$ After we cooled the bomb to room temperature and took out the vial, the content in the vial was evaporated to dryness in the specially designed glass evaporation chamber. The residue in the vial was dissolved in $0.45 \mathrm{ml}$ of $0.1 \mathrm{~mol} \mathrm{dm}^{-3}$ perchloric acid on warming and, finally, the total mass was weighed. Only $100 \mu \mathrm{l}$ of the sample solution thus obtained was subjected to the ICP-AES measurement for each metal determination. The calibration graph was also constructed with $100 \mu$ of standard solutions. The metal content in the fresh liver was calculated according to the following relation:

Content $(\mu \mathrm{g} / \mathrm{g})=$ Concentration found $(\mu \mathrm{g} / \mathrm{g}) \times$ Mass of final sample solution (g)/Fresh liver mass (g)

\section{Results and Discussion}

As evident from our previous work ${ }^{4}$, the injection volume of $100 \mu$ is effective for the determination of elements even by the ICP-AES. Judging from the reproducibility $(<1.6 \%, n=3)$ of the measurements obtained with the injection volume of $100 \mu l$, the one measurement for a metal is still reliable. The calibration graph obtained with $100 \mu \mathrm{l}$ injection gave a good straight line with a slightly lower sensitivity, compared with that obtained for continuous nebulization. In addition, the coexisting elements in the sample matrix gave no effect on either the signal or the baseline of four elements of interest under the present experimental conditions. The results obtained with the injection volume of $100 \mu \mathrm{l}$ are shown in Table 2. The
Table 2 Analytical results for 4 elements in fresh liver

\begin{tabular}{llcc}
\hline \multirow{2}{*}{ Element } & \multicolumn{3}{c}{${\text { Concentration } / \mu \mathrm{g} \mathrm{g} \mathrm{g}^{-1}}$} \\
\cline { 2 - 4 } & Found $^{\mathrm{a}}$ & Content $^{\mathrm{b}}$ & Weighed mean (range) $^{7}$ \\
\hline $\mathrm{Cd}$ & 0.403 & 4.94 & $3.13(0.52-4.94)$ \\
$\mathrm{Cu}$ & 2.83 & 34.7 & $7.37(3.2-14.7)$ \\
$\mathrm{Mn}$ & 0.283 & 3.47 & $1.02(0.5-1.91)$ \\
$\mathrm{Pb}$ & 0.115 & 1.41 & $1.28(0.81-2.3)$ \\
\hline
\end{tabular}

a. Metal concentration found in the final sample solution.

b. Metal content in fresh liver.

contents of cadmium and lead are in the range of normal levels. Manganese content is a bit higher, while copper content is much higher than the normal level. Higher copper concentration was correctly determined only by the "one-drop" ICP-AES, because ICP-AES gave a wider and more effective dynamic range for calibration. Judging from these data and the other results of metal analyses in the patient's hair and blood and from his latest symptoms, the diagnosis of his illness was not lead poisoning but a case of a plasma cell dyscrasia.

In conclusion, by the combined use of Teflon bomb method for sample decomposition in a small scale and "one-drop" ICP-AES, ppm level of elements of interest in minute and limited masses of fresh sample were successfully determined even by one measurement per element. If the "one-drop" method is applied to the simultaneous multi-element determination by multichannel ICP-AES, it could become a more effective method for determining more elements in limited masses of fresh biological tissues and also would play an important role for diagnosis of the abnormal metal metabolism or metal poisoning.

\section{References}

1. M. S. Cressor, Prog. Analyt. Atom. Spectrosc., 4, 219 (1981).

2. I. Kojima and C. lida, Analyst [London], 107, 1000 (1982).

3. C. Iida, Bunseki, 1983, 531.

4. T. Uchida, I. Kojima, C. Iida and K. Goto, Analyst [London], 111, 791 (1986).

5. I. Kojima, T. Uchida and C. Iida, Anal. Sci., 2, 225 (1986).

6. K. Goto, T. Uchida and C. Iida, Rev. Sci. Instrum., 54, 291 (1983).

7. G. V. Iyengar, W. E. Kollmer and H. J. M. Bowen, "The Elemental Composition of Human Tissues and Body Fluids", p. 65, Verlag Chemie, Weinheim, New York (1978).

(Received April 1, 1988)

(Accepted June 24, 1988) 